\title{
LA NUEVA ECOLOGICA El sentido político de la ecología en América Latina
}

\author{
Fernando Mires
}

En el presente trabajo se intentará demostrar que la Ecología en sí no encierra ningún discurso específico. Su discursividad depende, por lo tanto, del marco conceptual en donde se inserta el conocimiento ecológico. Estos marcos conceptuales están dominados en América Latina por «La Economía del Crecimiento», que en sus diversas expresiones convierten a la naturaleza y al ser humano en simples medios para alcanzar determinadas metas cuantitativas. En los últimos decenios ha comenzado a tener lugar, también en América Latina, un estilo de pensamiento que pretende subvertir el sentido puramente cuantitativista de la Economía Política vigente y que, integrando a la temática ecológica, busca crear las bases para una «Segunda Crítica a la Economía Política» que incorpore la noción de lo incuantificable (la naturaleza no tiene precio) en la reformulación de una teoría del valor. Particularmente intensivo ha sido el intento de teóricos marxistas o de inspiración marxista por incluir la temática ecológica en el discurso socialista. Si la Ecología puede ser la tabla de salvación de antiguos discursos, o la base para otro radicalmente diferente a los producidos en «el período de la modernización», es algo que trataré de discutir en este trabajo.

\section{LAS ILUSIONES DEL «SOCIALISMO VERDADERO»}

Quizás nos encontramos en uno de los momentos de ruptura histórica más profundos en los llamados Tiempos Modernos. Expresión, sólo expresión de esa ruptura, y como trataré de demostrar, no la ruptura misma, ha sido la bancarrota experimentada por los sistemas socialistas de Europa del Este. Pues si alguien llegó a pensar que el colapso de tales regímenes sólo afectaba en su "compresión de mundo» a los diferentes partidos comunistas, o a sus simpatizantes, se equivocó profundamente. Desde luego, no fueron pocos quienes entendiéndose como copartícipes de esa entelequia llamada «izquierda mundial» pensaron que aquello que se venía abajo sólo era el estalinismo y sus secuelas. Más todavía, no han sido pocos aquellos que llegaron a plantear que el derrumbe del estalinismo abría, al fin, las perspectivas para que hiciera su puesta en escena el «verdadero socialismo» (1). El «verdadero socialismo» o el «socialismo no

(1) «En tanto el estalinismo era considerado por cualquier persona como una especie de aborto del socialismo, el capitalismo, en los países capitalistas altamente industrializados, no tenía que temer a ninguna competencia. Pero si aceptamos lo ocurrido no como una etapa metafísica en el devenir, sino como una chance, entonces no se puede descartar que nos encontramos no al final, sino al comienzo de una era socialista" (Oskar Negt, "Das gebrochene Anfang), en Das Argument, 184, estalinista», vale decir, aquel socialismo virgen que viviendo sólo en las mentes de sus portadores, los izquierdistas que se llamaban a sí mismos «no dogmáticos», no había tenido la oportunidad (todavía) de ser llevado a la práctica.

Para los exponentes del «socialismo verdadero» -y éste es uno de sus principales argumentos- el capitalismo sólo «derrotó al estalinismo, pero no al socialismo». Más todavía: el triunfo del capitalismo, de acuerdo a las versiones más socorridas, hará posible que éste tenga que enfrentarse con sus propias contradicciones, pues ninguna de ellas ha sido resuelta (2). El capitalismo, argumentan, sigue viviendo de la explotación de los obreros, de la explotación del Tercer Mundo y - nuevo descubrimiento- de la explotación de la naturaleza. Es en ese marco ideológico donde la ecología aparece, ya no tanto como una ciencia, sino como la tabla de salvación de determinadas ideologías. Cómo es posible que, de pronto, la ecología se convierta en un recurso político después de haber sido, salvo honrosas excepciones, condenada al silencio más sepulcral no sólo por los representantes del «estalinismo», sino también por los del «socialismo verdadero», es una pregunta que queda sin respuesta. Y la no existencia de esa respuesta tiene sus razones: averiguar por qué la explotación de la naturaleza, y, por supuesto, la de sus consumidores más inmediatos, «los indios» y/o los campesinos, no tenía cabida dentro de un determinado discurso teórico, significa dudar de la vigencia de ese discurso. Porque si temas como el ecológico, el feminista y muchos otros no tuvieran cabida dentro del discurso socialista, no fue como consecuencia de «leves omisiones teóricas», sino debido a que ese discurso no dejaba en su propia estructura interna ningún hueco para el pensar ecológico. En otras palabras: responder a esa pregunta habría significado cuestionar el sentido progresivo de la historia, que es un rasgo común de todas las ideologías socialistas, tanto de las «estalinistas» como de las «verdaderas».

Ahora bien, si he comenzado un trabajo que sólo pretende mencionar algunas relaciones entre lo ecológico y lo político haciendo alusión a los «socialistas verdaderos», no ha sido porque aquí se intente presentar un nuevo "demonio». Por el contrario, mi planteamiento en ese sentido es que si

Cuademo 6, diciembre 1990, p. 922)

(2) La creencia en el «triunfo» del capitalismo, interiorizada por muchos socialistas es reaccionaria en un doble sentido: porque «inventa» un capitalismo omnimodo y omnipresente y porque escamotea a los revolucionarios que lucharon en contra de las despotías socialistas de sus respectivos países el enorme triunfo histórico obtenido. 
es imposible separar al socialismo que existió en la realidad, del socialismo virgen o «verdadero», tampoco sería justo asimilar todas las formas del pensamiento socialista al estalinismo. La historia del socialismo es también la historia de proyectos históricos derrotados en su propio interior. A la historia del socialismo pertenece Stalin, pero también Trotsky; Pol Pot, pero también Gramsci. Más todavía: aquí se sostiene que es políticamente necesario establecer relaciones de continuidad con algunos de esos proyectos; también desde una perspectiva ecológica o ecologista (3).

Por lo tanto, haber comenzado aludiendo al «socialismo verdadero» tiene una explicación. Ella deriva del hecho de que gran parte de la militancia de los movimientos ecológicos, tanto en Europa como en América Latina, proviene de izquierdas socialistas disidentes respecto a formas estalinistas («la nueva izquierda de los años sesenta», por ejemplo). Eso explica a su vez que en torno al tema ecológico confluyan diversas posibilidades. Una de ellas es la de reconstruir la antigua lógica del «cambio social» recurriendo a algunos elementos ecológicos «ad hoc». De acuerdo a esa orientación, lo ecológico sólo sería un recurso auxiliar que permite seguir adhiriendo a una idea de socialismo que se «comestiza» ecológicamente, pero que en lo sustancial no cuestiona radicalmente algunos aspectos que hacen a su propia identidad, como, por ejemplo, el sentido progresivo de la historia y, por eso mismo, a la noción de sociobiología del «desarrollo» económico.

Por cierto, no se niega aquí que una concepción teórica que se confronte con las formas que asumen los capitalismos en América Latina es mucho más efectiva si recurre a ciertas formas del conocimiento ecológico (utilizo conscientemente el término capitalismo en plural, discutiendo con ello aquella concepción ideológica heredada del monoteísmo medieval que hace del "sistema-único-mundial» la figura máxima de la Creación). Tampoco se niega que ese saber aplicado a las ciencias sociales pueda contener un enorme potencial anticapitalista. Pero hacer de la ecología un simple recurso ideológico anticapitalista, significa reducir enormemente el radio de acción político de la ecología. En ese sentido, el pensamiento ecológico quedaría limitado a denunciar los atentados en contra de la naturaleza cometidos por la penetración capitalista, perdiéndose así la posibilidad de ser incorporado en una discursividad que no se base en la simple negatividad de "lo capitalista», sino que además esté en condiciones de producir su propia afirmación o, lo que es parecido, de articular visionariamente diversas formas de concebir el porvenir.

Lo dicho nos sirve para referirnos a una de las principales limitaciones del «socialismo verdadero». Cuando supone que el triunfo del "capitalismo» no lo es tal puesto que no ha resuelto muchas de sus contradicciones, entre ellas con la naturaleza, los exponentes del "socialismo verdadero» se condenan a sí mismos a vivir sólo de problemas que «el capitalismo» no es capaz de resolver. De ese modo permanecen tan fijados al «capitalismo» como los propios capita-

(3) Por ejemplo, sería buena idea volver a leer los escritos de Bujarin acerca del "socialismo a paso de tortuga" y las relaciones no destructivas entre ciudadcampo que de ahi se derivan. listas reduciendo así su concepción de socialismo a su expresión más mínima: lo no-capitalista. Imposibilitados de crear su propia afirmación del futuro, o de imaginar un orden de cosas que sea algo más que la pura negatividad del que denuncian, terminan por echar la última paletada de tierra a una idea en que ellos mismos ya no pueden creer, puesto que en su pura negatividad ha sido despojada de la fuerza creadora de las fantasías trascendentes. Al alimentarse sólo de la miseria que produce «el capitalismo», convierten su propia ideología en miseria. ¿Qué puede extrañar, entonces, que los principales defensores de la naturaleza en América Latina, los indios, nunca se hayan sentido identificados con la idea del socialismo? Para la gran mayoría de ellos, y con mucha razón, el socialismo no es sino una de las muchas formas que asume «el desarrollo». Pero en nombre de ese desarrollo se les asesina a diario. Ahora, si es posible seguir siendo socialistas y renunciar a una concepción progresiva del desarrollo histórico, vale decir, si es posible que los «socialistas verdaderos» logren alguna vez imaginar un socialismo sin un proletariado como vanguardia, sin desarrollo de las fuerzas productivas (destructivas, en el lenguaje ecologista), sin «contradicción principal de clases», etcétera, es un problema teórico muy serio que ellos deben resolver. Pero en tanto ese problema no sea resuelto, puede pasar mucho tiempo. Y los problemas ecológicos (y no sólo los ecológicos) son demasiado urgentes como para seguirlos esperando.

\section{HACIA UNA NUEVA FORMACION DISCURSIVA}

Haberme referido al significado de «los socialismos verdaderos» tiene además otra explicación. Desde hace algunos decenios, en diferentes países de la tierra, está teniendo lugar una formación discursiva que habiéndose planteado originariamente sólo en contra del «discurso de la modernidad», ha ido produciendo en su devenir afirmaciones constructivas que apuntan hacia nuevas formas de concebir la realidad de lo social. No es casualidad que para distintos movimientos sociales, étnicos y nacionales de nuestro tiempo, el lema distintivo de sus luchas no sea ni el progreso, ni el crecimiento económico, ni la industrialización a todo precio, como fue el caso de los movimientos burgueses del siglo pasado y de los movimientos obreros y socialistas del siglo XX. Por el contrario, recurriendo a formas de conocimiento ecológico, se orientan fundamentalmente a realizar luchas de resistencia en contra de las expresiones más agresivas de la modernidad, defendiendo tradiciones y territorios amenazados frente al avance de las llamadas «fuerzas productivas». Ahora bien: tratar de entender la enorme complejidad de tales movilizaciones sólo desde una perspectiva socialista, por más «verdadera» que ella sea, significaría limitar y desvirtuar ideológica y prácticamente el sentido y carácter de los procesos mencionados. Naturalmente, no toda interpretación «materialista y dialéctica» es falsa sólo por serlo, y sin duda, tales interpretaciones trabajan con elementos extraídos de la realidad concreta. Pero convengamos que ni en su construcción originaria (Marx et al.) ni en su construcción histórica (esto es, lo que el socialismo llegó 
históricamente a ser) no hay un lugar muy amplio para entender el sentido y carácter de los movimientos ecológicos (y agreguemos feministas, étnicos, religiosos, etcétera). En otras palabras, ninguna teoría socialista puede dar cuenta teórica de tales expresiones, debido a la simple razón de que el socialismo no fue construido, ni teórica ni históricamente, para dar cuenta de ellas. Las teorías socialistas, en sus más variadas formas, pueden dar cuenta de la realidad que con su instrumentario conceptual logran todavía aprehender. Se podría decir, en este sentido, del marxismo lo mismo que se podría decir de todas las disciplinas del pensamiento: Es absolutamente verdadero... siempre y cuando se piense en términos absolutamente marxistas. Pero frente a los movimientos mencionados, las teorías socialistas no ofrecen respuestas, o por lo menos, para muchos de sus actores ya no ofrecen las respuestas más radicales. Es posible afirmar de ellas quizá lo que afirmó Marx de las burguesías europeas del siglo XIX: han entrado a su forma conservadora de vida.

\section{POR UNA RACIONALIDAD NO RACIONALISTA}

Lo que es válido para las teorías socialistas, lo es en cierto modo también para otras "concepciones del mundo» de índole racionalista, inherentes al (mal llamado) período de la modernidad. En buenas cuentas, y quizás ésta es una tercera razón por la cual he comenzado aludiendo al «socialismo verdadero», el socialismo representa la expresión más radical del pensamiento racionalista europeo. De tal modo que el verdadero sujeto que aquí se cuestiona es al racionalismo (no confundir con racionalidad) y al socialismo sólo en cuanto una de sus expresiones. Para ser más preciso: en el proceso de construcción del pensamiento moderno, fueron, desde un comienzo, formándose dos corrientes: una humanista, y otra racionalista. Ambas corrientes, tributarias al fin y al cabo del mismo cauce, se cruzan, en su recorrido, intermitentemente. Ahora bien, en el caso de la formación discursiva del pensamiento socialista, predominaron, exigentemente, las corrientes racionalistas, en tanto que las corrientes humanistas se mantuvieron en una situación bastante marginal. El leninismo, el estalinismo, el althuserianismo de los años sesenta (Althusser textual: «el marxismo no es un humanismo»), son ejemplos del pensamiento racionalista. Gramsci, Korsch, Marátegui, entre otros muchos, representan la racionalidad del pensamiento humanista. La expresión más extrema del pensamiento racionalista se encuentra, no obstante, más que en la teoría, en aquella realidad que fueron los regímenes socialistas existentes y reales. No es precisamente una casualidad que el predominio de la razón instrumental en la forma rabiosamente industrialista que es posible imaginar, haya dejado los países en que el socialismo fue impuesto, al borde de la bacarrota ecológica y, por eso mismo, de la económica. Ahora bien, la enorme tarea teórica que los socialistas tienen por delante es la de liberar al pensamiento humanista de «la lógica del racionalismo puro», trabajo de Sísifo que supone no sólo la continuación del pensamiento socialista, sino que —en los propios términos dialéctico-marxistas- su superación (teórica e histórica). En ese sentido, la recurrencia teórica al pensamiento ecológico, si bien es decisiva en el marco de ese proceso de superación, no la asegura por sí sola. En palabras mucho más simples: no basta reemplazar la contradicción burguesía-proletariado por la de naturaleza-capital, ni a Vietnam por la Amazonia para producir un nuevo estilo de pensamiento; y ello es así porque la pura recurrencia ideológica a la ecología no cambia en nada el sentido y carácter de un discurso. Como he afirmado en otras ocasio-nes (4) la ecología en si no es un discurso, es, sí, un recur-so, y de él se pueden servir muchas ideologías, como de he-cho ha ocurrido en la realidad.

\section{LAS RAZONES DEL «BOOM» ECOLOGICO}

Que la ecología en sí no sea un discurso, no significa afirmar que ella tiene un sentido político neutral. No existe, en verdad, ninguna ciencia que pueda aducir inocencia política. Las ciencias, en este caso la ecología, se construyen en el marco determinado por estilos de pensamiento que en su estructura no son necesariamente científicos. Ya el médico polaco Ludwig Fleck demostraba muy lógicamente, hace muchos años, cómo el llamado pensamiento científico se alimenta constantemente del pensamiento profano, dando forma científica a lo que no es sino superstición, religión, prejuicio y lugares comunes. A la vez, el pensamiento profano también se alimenta - según Fleck- del pensamiento científico «puro», pues muchas veces este último no era más que su sublimación (5). Hasta en los libros más especializados de ecología se encuentra la presencia de los ecólogos que los han escrito quienes, actores de su propio tiempo, transportaban hacia el interior de la ecología criterios y estilos de pensamiento que no provenían precisamente de la ecología.

La razón más visible parece provenir del impacto producido por las catástrofes ecológicas de nuestro tiempo. Sin embargo, el hecho de que ellas sean percibidas con tanta atención, lo que no siempre ocurría en el pasado, significa que también en los últimos tiempos ha despertado una nueva sensibilidad. Esa nueva sensibilidad tiene que ver con el descrédito en que han entrado las teorías de modernización vigentes, descrédito que a su vez tiene que ver con la no verificación práctica de las promesas contenidas en tales teorias. Por cierto, en algunos países, la modernización se ha traducido en altas tasas de crecimiento y de consumo; pero los riesgos contenidos precisamente en la imposición de las políticas modernizadoras parecen, en muchos casos, ser bastante superiores a sus «éxitos». Para no hablar sólo de la permanente posibilidad de estallido de reactores atómicos como el de Schernobyl, basta referirse al riesgo que hoy implica respirar el aire envenenado de las ciudades industrializadas; a la pérdida de tiempo que significa viajar en automóvil en carreteras atestadas y plagadas de cadáveres cuyo número supera con creces a los de las más encarnizadas guerras; o simplemente tomar el sol en alguna playa (ya que bañarse en el mar es una aventura que pertenece al pa-

(4) Fernando Mires, «El discurso de la Naturaleza», San José, 1990, Santiago, 1990.

(5) L. Fleck, "Enstsehung und Entwicklung einer Wissenchaftliche Tatsche», Frankfurt, 1980. 
sado) cuyos rayos desprovistos de protección ozónica constituyen la mejor garantía para morir de cáncer.

\section{EL SUBDESARROLLO DEL PENSAMIENTO ECOLOGICO LATINOAMERICANO}

Si en algunos países el descrédito respecto a los procesos de modernización es grande, cabría esperar que en países pobres, como son los latinoamericanos, el escepticismo frente a «la ideología del progreso» debería ser mucho mayor. Esto es, sin embargo, relativo. Por cierto, hay una larga resistencia de campesinos e indígenas frente a los avances de la modernidad, la que data desde la fundación de las propias repúblicas, resistencia que exige entre muchos otros puntos, el respeto por los fundamentos naturales de la existencia humana. Sin embargo, a diferencia de lo que ocurre en algunos países europeos, en América Latina los temas ecológicos están haciendo ahora su entrada al nivel de la política; por lo menos al nivel de la política oficial. El hecho expuesto no deja de llamar la atención si se considera que los efectos de la devastación ecológica en América Latina parecen ser mucho más graves que en otros lugares de la Tierra. Sin embargo, esta misma constatación puede ser deducida como una de las razones principales que explican la marginación de los temas ecológicos respecto al mundo de la política. En efecto: los daños ecológicos en América Latina han alcanzado tal grado de magnitud que tomarlos en cuenta significaría admitir el fracaso pleno de proyectos económicos que se vienen poniendo en práctica desde ya hace mucho tiempo. En otras palabras: asumir en su verdadera intensidad la temática ecológica implicaría además asumir un nuevo tipo de radicalidad social que pocas de las fuerzas políticas establecidas en los gobiernos o en la oposición podrían asumir sin caer en el peligro de negarse a sí mismas, o por lo menos, sin cuestionar su propia historia. Pues si ha habido un continente en que la modernidad, en sus formas industrialistas y «desarrollistas», fue convertida por «expertos» económicos y políticos en una especie de religión, ése es América Latina.

No hay que olvidar que en nombre de la civilización y el progreso durante el siglo XIX fueron en nuestro continente diezmadas las poblaciones aborígenes, y sus tierras convertidas en propiedad de los grandes hacendados, quienes, apoyando a conservadores o a liberales, contaron con el beneplácito de los respectivos Estados «nacionales». Hoy en día es muy importante recordar esos hechos, sobre todo cuando se quiere inculpar del genocidio cometido a las poblaciones indígenas sólo al colonialismo español y portugués. El «Apartheid» y el aniquilamiento sistemático de las poblaciones autóctonas llevado a cabo en la mayoría de nuestras repúblicas durante el siglo XIX, tiene muy pocos parangones en la historia.

De la misma manera, en nuestro siglo, y en nombre del "desarrollo», han sido destruidos sistemáticamente los fundamentos de subsistencia natural de poblaciones agrarias, obligando a campesinos indígenas a invadir ciudades, convertidas hoy en metrópolis productoras de miseria social y ecológica. En cada ciudad latinoamericana existe, ya no sólo potencialmente, una Calcuta, y la «marginalidad», la miseria y la «informalidad», lejos de ser fenómenos colaterales al «desarrollo», constituyen su verdadera realidad. Que tal realidad es también consecuencia de la destrucción ecológica, es algo que sabe todo el mundo; menos los "economistas del crecimiento».

Quizá no hay una expresión más sintomática de los resultados del «desarrollo» que la aparición del cólera, sobre todo en un país como Perú al que la mayoría de los «desarrollistas» hasta hace muy pocos años consideraban como «viable». Digo expresión sintomática porque el cólera no sólo surge como consecuencia de la destrucción de la naturaleza y de sus habitantes, sino además porque es considerada una enfermedad del siglo pasado. La reaparición del cólera es también entonces una de las pruebas más evidentes del tipo de "progreso» que produce el desarrollo latinoamericano: el regreso al pasado, sólo que en peores condiciones que antes. Después de «los tiempos del cólera», no serán muchos los economistas del «crecimiento» que se atreverán a seguir afirmando que son los ecologistas quienes se oponen al «progreso». Son ellos mismos, quienes insistiendo en su lógica evolucionista (o desarrollista, da lo mismo) reproducen los momentos más escalofriantes del pasado, en aras de un futuro que nunca se convierte en realidad.

Asumir la cuestión ecológica, o por lo menos tomar algunos de sus enunciados en serio, significaría pues la negación de gran parte de la lógica en que se han basado las políticas de desarrollo de nuestro continente. En otras palabras: significaría reconocer la bancarrota del desarrollismo, tanto en sus expresiones de «derecha» como de «izquierda», lo que a su vez significaría reconocer lo superfluas que son las cuantiosas inversiones de dólares en programas e institutos «de desarrollo». De este modo, la ecología no puede ser para los desarrollistas sino una palabra de moda a la que hay que desautorizar «científicamente» (y cuando no se pueda, utilizar demagógicamente) aduciendo que es un lujo que solamente se pueden otorgar los países ricos, ya que «nuestro» principal problema es «la superación de la miseria», la que sólo es posible alcanzando el desarrollo, entendido esto como «crecimiento económico». Que precisamente la destrucción de la fuente de todos los capitales, y de los fundamentos materiales de la reproducción social, la naturaleza, impide la formulación de una verdadera política económica, es un «detalle» que la absurda «cientificidad desarrollista» no se encuentra en condiciones de captar.

\section{LAS ALIANZAS EN CONTRA DE LA NATURALEZA}

Hay además otra razón que explica por qué en los círculos dirigentes de los países latinoamericanos existe una actitud tan negativa respecto a la ecología. «La economía del crecimiento»y/o, el «desarrollismo», no existe sólo en las mentes de los "expertos», sino que además es un componente ideológico de alianzas sociales, o lo que es igual, es un resultado de relaciones de poder. Efectivamente, desde que comenzaron a ponerse en práctica las políticas de modernización y desarrollo en América Latina, han tendido a establecerse «pactos» sociales que se diferencian por su am- 
plitud, pero no tanto por sus contenidos esenciales. A riesgo de simplificar excesivamente los problemas me permitiré diferenciar tres esquemas de alianza social en los cuales han reposado los proyectos mencionados.

1. El esquema oligárquico tradicional, que supone la hegemonía de la oligarquía agrominera exportadora, con escasa participación de los "sectores medios» y del sector mercantil. El hecho de que sea la oligarquía el sector hegemónico no descarta por cierto la posibilidad de la puesta en práctica de proyectos de modernización. Por el contrario, no olvidemos que en el oligarca México de la prerrevolución, durante el gobierno de Porfirio Díaz, fueron llevados a cabo intensivos proyectos de industrialización. De la misma manera, es pertinente recordar que Argentina, uno de los países más industrializados del continente, no fue industrializado por la «burguesía», como generalmente se afirma, sino por los sectores llamados oligárquicos. Lo que sí caracteriza a la modernización de tipo oligárquico es su carácter de «enclave», y por consiguiente, la enorme relevancia que alcanzan en ellos los capitales extranjeros. Dado el tipo de relaciones sociales que exige el predominio de la oligarquía, la implantación de este esquema pasa necesariamente por la intocabilidad de los sistemas de latifundio y de hacienda.

2. El esquema nacional populista es aquel que comenzó a llevarse a la práctica en torno a la consigna de «la sustitución de las importaciones» a partir de los años treinta y como consecuencia de la contracción externa de capitales experimentada durante la gran crisis mundial de 1929. La política de sustitución de importaciones coincide, pues, con el fenómeno que algunos sociólogos tradicionales denominaron «el ascenso de los sectores medios» (Germani, Graciarena, Di Tella, etcétera) e implica un tipo de concertación social que además de la oligarquía incorpora parte de los sectores medios dependientes del Estado y, en algunos casos (Argentina, Chile, México), muy limitadas fracciones del movimiento obrero sindicalmente organizado. El pacto nacional-populista no tiene, en consecuencia, por lo menos en sus primeras fases, un carácter necesariamente oligárquico. Por el contrario, el concurso de los sectores latifundistas era fundamental para convertir los excedentes pasivos en capitales productivos. La necesidad del apoyo oligárquico implicó que el proyecto de industrialización sustitutiva hubiese renunciado a implementar transformaciones sociales en el sector agrario. De la misma manera, a contracorriente de lo que se afirma comúnmente, la llamada sustitución de importaciones se realizó en gran parte gracias al concurso de los capitales extranjeros, cuyas exigencias no pasaban precisamente por el respeto a la naturaleza. Fue a partir de la experiencia de los años treinta, cuando economistas militantemente organizados en instituciones como la CEPAL, intentaron conferir un estatuto teórico a la experiencia "sustitutivista», estableciendo la industrialización como objeto a alcanzar de acuerdo a determinadas «etapas del crecimiento económico», deducidas del «desarrollo» de algunos países europeos, especialmente de Inglaterra (6). De este modo, la modernización se transformó en "desarrollismo», entendido éste como sinónimo de industrialización. La imposibilidad

(6) Especialmente, siguiendo las lineas «rostowianas» (W.W. Rostow, «The Stages of Economic Growth», Cambridge, 1960). de que esta industrialización pudiera llevarse hasta sus últimas consecuencias con la participación de las oligarquías trajo consigo que durante los años cincuenta, en la propia CEPAL, comenzara a ser planteada insistentemente la necesidad de que fueran llevadas a cabo reformas estructurales «antioligárquicas», sobre todo «reformas agrarias», proyectos que llevados a la práctica en algunos países (Chile, Perú) traerían consigo la ruptura del pacto oligárquico. La industrialización a todo precio es una obsesión fanática del desarrollismo, y la destrucción de relaciones sociales (las ecológicas no existen para los desarrollistas) que ello implica es, para sus exponentes, un precio necesario a pagar en aras del supuesto progreso económico que emergerá como consecuencia de esa supuesta industrialización. El lema «tradición-modernidad» de la modernización desarrollista sustituye al de «civilización-barbarie» de la modernización oligárquica. Teorías sociológicas como la de la «marginalidad», por ejemplo, confeccionadas «ad hoc» con el propósito de integrar socialmente a los sectores sociales que desintegra el desarrollo económico, pueden ser consideradas en ese sentido como simples subproductos ideológicos del «desarrollismo». Sin embargo, la alianza social sobre la cual reposa el proyecto sustitutivista de desarrollo era por lo general demasiado amplio, lo que implica compensar la lealtad de sus adherentes, razón por la cual nunca fue posible implementar sin recurrir a políticas inflacionarias, con la consiguiente inestabilidad política que ellas han traído consigo. Precisamente los impases ocasionados por el desarrollismo sustitutivista abrieron las compuertas para que, como reacción, comenzara a tomar parte un tercer proyecto modernizador, muy vigente en nuestros días: el neoliberalismo.

3. El esquema neoliberal pone acento preferencialmente en los programas de estabilización monetaria como condición fundamental del «desarrollo». Por eso es llamado también monetarismo. En realidad, el esquema no tiene nada de nuevo; sin embargo, ha alcanzando relevancia debido a algunas condiciones muy propicias. Una fue, sin duda, el caos inflacionario provocado por las alianzas nacional-populistas al intentar compensar la enorme amplitud de las clientelas que lo rodeaban, lo que desde un punto de vista tecnocrático exigía la puesta en práctica de medidas estabilizadoras las que a su vez no eran posibles de realizar sin desahuciar las alianzas contraídas en el poder durante el período «sustitutivista». Otra condición propicia para el neoliberalismo fue la reorganización internacional de las relaciones económicas como resultado de «una nueva división internacional del trabajo» derivada del desarrollo tecnológico que tenía lugar en algunos países altamente industrializados. En efecto, en los tiempos de «la tercera revolución industrial», muchos países no industrializados deberán despedirse, y por mucho tiempo, de la posibilidad de alcanzar las supuestas metal del desarrollo por medio de la vía industrial, por la sencilla razón de que el interés para que ello ocurra ha des-aparecido en los centros principales de decisión internacional. En otras palabras: el tipo de producción basado en el predominio de la industria pesada y en el consumo de masas, denominado por algunos teóricos como «fordismo» (7) inició ya su retirada en los propios países en que

(7) El concepto de «fordismo» proviene de Gramsci y fue reactualizando por Michael Aglietta. 
tuvo origen, convirtiéndose en superflua su aplicación en los llamados países "subdesarrollados». A tales países no les queda más alternativa para subsistir en los mercados internacionales que afirmarse en su papel de exportadores de productos primarios. De este modo, las tareas «históricas» que se proponen los regímenes neoliberales son principalmente tres: a) Detener la espiral inflacionaria, para lo cual se hace necesario aplicar política de «shock» que reduzca drásticamente sueldos y salarios y por lo mismo, desahuciar la alianza industrialista a los sectores sindicales más organizados (ya que los menos organizados nunca formaron parte de ella). b) Desmantelar o privatizar gran parte del sector industrial tradicional, llevando a cabo despidos en masa. c) Generar la infraestructura necesaria para introducir una política de «diversificación de exportaciones» la que como consigna del momento entra a reemplazar a la de la «sustitución de las importaciones».

Como se puede deducir, las tres tareas principales planteadas al neoliberalismo hacen prácticamente imposible que éstas puedan realizarse prescindiendo de regímenes políticos autoritarios, o simplemente dictatoriales. No es extraño entonces que el país pionero en «la diversificación de las exportaciones» sea el Chile que se formó económicamente durante la dictadura de Pinochet. Con esto no se quiere decir que las dictaduras latinoamericanas del pasado reciente sean productos del neoliberalismo. Pero tampoco se quiere decir lo contrario: que el neoliberalismo es producto de las dictaduras. Pues si pensamos que la Economía es la Economía Política; y lo es, ni lo uno ni lo otro pueden diferenciarse ni separarse; más bien lo uno es condición de lo otro.

Tampoco debe inducir a sorpresas el hecho de que durante el período de los regímenes autoritarios se hayan perpetrado los ataques más despiadados a la naturaleza. Fue por ejemplo durante la era de los gobiernos militares cuando en Brasil, la Amazonia, con todos sus habitantes, fue puesta en valor (8). Para los militares, en efecto, la Amazonia representaba un problema geopolítico, pues para ellos no era más que un territorio "vacío» al que había que "anexar», integrándola a aquella economía supuestamente controlada por el Estado Nacional. Para los economistas brasileños, a su vez, la enorme riqueza vegetacional y genética contenida en los milenarios bosques, carecía de «valor» (para la Economía del Crecimiento sólo existe «valor» en cuanto las cosas y los seres humanos son mercantilizados; por esas razones, las vidas de miles de indios amazónicos también carecía, para ellos, de «valor»). Así se fue formando aquello que en otros trabajos he denominado como modo de producción amazónico, que puede definirse como un complejo económico, político y militar orientado objetivamente a la destrucción de la naturaleza en función de la obtención inmediata de ganancias las que, en última instancia, son absorbidas por el mercado mundial (9).

Ahora bien, una de las premisas en la realización de las políticas de diversificación de exportaciones es la capacidad de responder inmediatamente a las demandas ejercidas por

(8) La teoría de la upuesta en valon» ha sido trabajada intensivamente por Elmar Altvater (E. Altvater, "Sachszwang Weltmar», Hamburg, 1987. «Die Zukunft des Marktes», Münster, 1991).

(9) Fernando Mires, op. cit., 1190, pp. 113-129. También, F. Mires «El discurso de la indianidad", San José, 1991, pp. 109-118. los mercados externos. En tal sentido, ya se dejan adivinar las consecuencias que ello implica para la reproducción de la naturaleza. Los campos de los países latinoamericanos hace mucho tiempo que dejaron de producir para sus habitantes. Se siembra y se cosecha sólo lo que es exportable, haciéndose muchas veces caso omiso de las condiciones naturales de la reproducción. No importa que los ayer fértiles terrenos mañana sean desiertos. Lo que importa es el momento "económico». De este modo tampoco extraña que el resultado glorioso de las políticas de «diversificación de las exportaciones» sea, al final, la erosión y, en consecuencia, la ruina económica de los productores más inmediatos: y los más inmediatos son los indios y los campesinos. Debido a esa razón es imposible separar en América Latina a «la cuestión ecológica» de «la cuestión agraria» y de «la cuestión indígena». La ecología no sólo es el tema del «medio ambiente» como intentan degradarla los «economistas del crecimiento». En América Latina es necesariamente un tema social y político, y muy explosivo.

Por supuesto, hay grandes diferencias entre los tres esquemas mencionados. Pero, pese a esas diferencias, hay algunos aspectos que poseen en común. Para comenzar, los tres son esquemas de modernización. Los tres entienden a la modernización como sinónimo de desarrollo, y los tres entienden el desarrollo como sinónimo de crecimiento económico, el que sólo puede ser alcanzado mediante la aplicación de la vía industrial (10). Los tres, al mismo tiempo, sostienen que el proceso de desarrollo industrial no puede llevarse a cabo sin que sea realizado un proceso previo de acumulación. Aunque ninguno de los tres esquemas lo establece literalmente, resulta obvio que la acumulación de capitales sólo puede ser lograda mediante la explotación sistemática de sectores de la población y, por supuesto, de la naturaleza. En tal sentido, los tres esquemas nombrados han pretendido rodearse de un aura científica. Pero, como suele ocurrir, la supuesta cientificidad de tales esquemas no es más que la reedición, en un lenguaje sofisticado, de las más grandes vulgaridades, prejuicio y creencias, animados en el pensamiento colectivo. En efecto: la lógica común que poseen, en el sentido de que el crecimiento económico sólo aparece como posible si se establecen «precios» que hay que pagar, no proviene de ninguna ciencia sino de un tipo de religiosidad medieval que afirmaba que para alcanzar el paraíso era necesario convertir este mundo en un lugar de expiaciones. Lo que han hecho los «economista del crecimiento» al establecer casi dogmáticamente la relación «costos-beneficios» es simplemente dar un cariz científico a este tipo de bárbara religiosidad. El pequeño problema es que aquellos que tienen que pagar los costos establecidos son siempre los más pobres y débiles, para quienes la vida se transforma en una permanente expiación de pecados que no han cometido jamás, y la esperanza del paraíso, en un infierno que, por lo menos para ellos, no tiene final. En el sentido expuesto, asumir «la cuestión ecológica» no signi-

(10) Podría argumentarse que el «ultraliberalismo» no es industrialista ya que bajo su dominación han tenido lugar verdaderos desmantelamientos de las industrias locales. Pero esa es sólo la apariencia del problema. Los neoliberales arrasaron con las industrias locales, es cierto. Pero lo hicieron con la esperanza de que llegaran a establecerse, y de una manera masiva, las industrias extranjeras. Si ellas no llegaron, ése es otro problema. 
fica agregar un nuevo tema en los programas vigentes de desarrollo. Se trata, por el contrario, de subvertir la propia noción biologista (o evolucionista) del desarrollo económico, por medio de la configuración de un nuevo tipo de radicalidad social que permita la formación de alianzas sociales que incluyan los intereses de la naturaleza que son, en primer lugar, los de sus consumidores más inmediatos, pero que en segundo lugar son los de todos nosotros.

\section{LA POLITICIDAD DEL SABER ECOLOGICO}

Frente a aquel estilo de pensamiento racionalista sustentado por la «Economía del Crecimiento» y que en América Latina ha alcanzado quizá sus expresiones más radicales, se ha ido constituyendo, en los últimos años, otro estilo de pensamiento que, recurriendo a la ecología, comienza a levantarse como alternativa, generando, paralelamente, una visión del mundo que ya no es sólo la negación que discute, sino que, en su expansión, crea sus propias afirmaciones. De este modo, frente a lo tecnológicamente arriesgado, el nuevo estilo de pensamiento propone lo tecnológicamente «adecuado»; frente a los gastos excesivos de energía, opone como alternativa la utilización de los recursos renovables; frente a la especialización extrema, aboga por una socialización de los conocimientos técnicos y científicos; frente a la producción en masa, propone el apoyo a la producción artesanal y a las cooperativas locales y regionales de libres productores asociados; frente a la vida en pequeñas familias encapsuladas, opone la idea de comunidad; al predominio urbano, opone una vida en contacto con lo rural; frente a la destrucción indiscriminada de la naturaleza, afirma los principios del equilibrio ecológico; frente al predominio del mercado mundial, surge la idea de los mercados interregionales, o simplemente locales; frente a la noción del crecimiento, opone la noción de escasez; frente al aislacionismo, opone la noción de «convivencia»; frente a la acumulación, el ahorro; frente al individualismo opone la reciprocidad; frente al armamentismo, se levantan los movimientos pacifistas; frente al ideal de obrero joven, no mayor de treinta y cinco años, opone la producción familiar con participación de niños y ancianos; frente a lo centralizado, opone lo local; frente a lo complicado, lo simple; frente a las «soluciones finales», soluciones parciales y pragmáticas; frente a los monocultivos, la diversificación de la agricultura; frente al primero de lo cuantitativo, el primado de lo cualitativo; frente a la producción de alimentos por medio de industrias especializadas, la coparticipación de la población en la producción de sus propios alimentos; frente a la descentralización de las culturas, levanta la defensa de las tradiciones culturales y de las comunidades indígenas; frente a la separación infranqueable entre el mundo del trabajo y de la vida, proclama la integración del placer en el trabajo; frente al ideal de la homogeneidad, el ideal de la diversidad; frente a lo inmenso, lo pequeño.

Como se puede ver, se trata de un estilo de pensamiento que articula distintos objetos, a veces contradictorios entre sí. Ello explica por qué la tendencia preferencial para hacerse presente en la política es la de movimientos sociales. Porque un movimiento social, a diferencia de un partido político, puede integrar en sí mismo lo contradictorio sin que, paradójicamente, eso signifique una contradicción, pues la naturaleza de un movimiento social es de por sí contradictoria (o si no, no sería movimiento).

Ahora bien, ese estilo de pensamiento ha integrado entre sus muchos objetivos a la ecología. ¿Qué se quiere decir con ello? Nada más simple: que dentro de ese estilo de pensamiento la ecología no existe en una situación estática, sino dinámicamente, pues convive e intercambia sus «formas de ser" con otros objetos, transformándolos a ellos, aunque transformándose también, en ese incesante proceso de intercambio, a sí misma. Esa no es una tarea difícil para la ecología, pues se trata de una ciencia que hace de las relaciones de intercambio (con los seres vivos entre sí y respecto a su medio ambiente) un objeto particular.

Sin embargo, para que aquel nuevo estilo de pensamiento pudiera hacerse presente al nivel de la política, fue necesario un largo proceso. Así, mirando retroactivamente esa realidad, es necesario revalorar a aquellos pensadores que en los años de apogeo del industrialismo se atrevieron a plantear sus posiciones. Los trabajos de Lewis Munford relativos a la «Megamaschina» son todavía muy actuales (11). Los llamamientos casi proféticos de Ivan Illich para establecer relaciones convivales, son indudablemente precursores del estilo de pensamiento que hoy día avanza por los espacios minados de la producción cultural (12). El libro de E. F. Schumacher, Small is Beautiful, alabando la producción en pequeña escala, pese a su doble carácter (pues al mismo tiempo que se pronuncia en contra de la producción en masa es un abogado de la nueva tecnología, la que de por sí no soluciona ningún problema) también constituye un hito histórico en la creación de aquella conciencia ecológica que avanza desmontando pieza por pieza el «discurso del desarrollo» (13).

El "discurso del desarrollo», que en América Latina constituye la expresión más radical de la modernización, se ve cuestionado, no ya en alguna de sus formas, como ocurrió en el pasado reciente, sino en su contenido esencial. En el sentido señalado, algunos observadores han creído ver la existencia de una contradicción entre Economía y Ecología. La contradicción, empero, es aparente. La verdadera contradicción existe en el interior de la propia Economía como ciencia, y no al exterior de ella. Por un lado, una ciencia económica que ignora en absoluto la participación de la naturaleza en los procesos económicos. Por otro, una ciencia económica que recurriendo al saber ecológico, comienza a comprender que dilapidando los recursos de la naturaleza, sólo es posible producir hambre, miseria y muerte (es decir, una Anti-Economía). De lo que se trata, pues, no es de negar la Economía por medio de la Ecología, sino que por el contrario: reivindicar la Economía devolviéndola a lo que fue originariamente, y a lo que nunca debió haber dejado de ser: ciencia que administra la escasez (y los recursos actuales naturales son escasos) y no ciencia que produce el crecimiento a cualquier precio. A fin de aclarar este enunciado,

(11) L. Munford, «Mythos des Maschine», Frankfurt, 1977

(12) I. Illich, «Selbstbegrenzung»), Reinbeck, 1975

(13) F. F. Schumacher, «Die Ruckehr zum menschlichen Maß», Hamburg, 1977 
permítaseme mostrar dos ideas que mediante el saber ecológico son cuestionadas en el saber economicista (en América Latina: desarrollista).

1. La idea de que sólo lo cuantificable es económico. Tal idea es una de las vulgarizaciones más grandes del pensamiento racionalista moderno. Sin embargo, hoy día comienza a percibirse que los daños ecológicos que produce la «economía del crecimiento» son incalculables e incuantificables. Pongamos un ejemplo: como es sabido, a consecuencia de la deforestación que se viene practicando sistemáticamente en los territorios amazónicos (así como en otras zonas boscosas) es intensificado el conocido efecto de «invernadero» sobre la Tierra, con los consiguientes aumentos de temperatura. Esto podría causar el derretimiento de las capas polares, lo que a su vez implicaría un aumento en el nivel del mar y con ello, desbordes en los sectores costeros que inundarían ciudades como Nueva York. ¿Qué precios tendrían esas ciudades si todos los riesgos ecológicos fueran computables? Como eso no se puede saber, los economistas del crecimiento, en lugar de proponer el fin de la deforestación, abogan por ella. Desde su perspectiva, sólo científicamente es válido lo cuantificable. Más allá de la lógica de las cantidades puras sólo existe, para ellos, la nada. Pero nadie en la vida real es tan estúpido para poner las manos en el fuego porque no sabe cuánto se queman. Lo único que importa saber es que se queman. Sin embargo, los economistas del crecimiento están dispuestos a arriesgar a miles de seres humanos por la sencilla razón de que todavía no poseen el cálculo exacto de cuántas serán las personas que perderán la vida.

Particularmente intensiva ha sido la discusión en torno a la cuantitividad de los valores de la naturaleza entre los economistas marxistas. Algunos de ellos, sensibilizados por el auge del pensamiento ecológico, han intentado enriquecer la teoría marxista del valor, agregando a ella la parte de la naturaleza que se pierde en el proceso de producción (14), con lo que, de paso, la propia «composición orgánica del capital» debería ser modificada. Autores marxistas como Altvater (15), reconociendo la importancia de la naturaleza como "fuente de riqueza», alegan que la naturaleza no produce valor pues no es mercancía, como la fuerza de trabajo. Con ello olvida que la operación de Marx al transformar teóricamente la fuerza de trabajo en mercancía, en tanto la fuerza de trabajo es naturaleza corporizada, sólo es una operación analógica, pues la fuerza de trabajo, como la naturaleza, no es por «naturaleza» mercancía. Ahora bien, la simple existencia de esas discusiones que en algunos círculos amenazan tomar características bizantinas, nos muestra cuán profundo ha entrado el pensar ecológico al interior de las propias teorías racionalistas y cuán importante es realizar lo que en otro trabajo he denominado como «una Segunda Crítica a la Economía Política» (16) que no sólo enriquezca, sino que además subvierta las teorías del valor existentes al incorporar a los criterios establecidos en los procesos de cálculo, valores económicos no cuantifica-

\footnotetext{
(14) Hans Immler/Wolfdietrich Schmied-Kowarzik, «Marx und die Naturfrage», Hamburg, 1984.

(15) E. Altvater, op. cit., 1991, pp. 253-255.

(16) F. Mires, op. cit., 1990, pp. 41-43.
}

bles. ¿Cuántas vidas vale un árbol? Es una pregunta, sin duda. Pero al mismo tiempo, son ese tipo de preguntas las que revelan la absoluta miseria de la «economía del crecimiento».

2. La idea de la infinitud del tiempo económico. Decir que los recursos naturales no son infinitos, es una trivialidad. Decir por lo tanto que el progreso no puede ser infinito, es una triviali-dad más grande. Sin embargo, si los «economistas del crecimiento» latinoamericanos no creyeran en esas trivialidades, el "desarrollo» latinoamericano nunca habría tomado las formas perversas que hoy asume. Sólo el empleo del concepto «crecer»es, desde el punto de vista de una economía que se sirve de la ecología, un absurdo, pues todo crecimiento de la producción implica un decrecimiento de los productos energéticos, algunos de los cuales son para siempre irrecuperables.

La interdisciplinaridad, tan necesaria hoy en día para repensar el sentido de los procesos económicos, ha obligado a algunos economistas a introducir conceptos que habitaban en laboratorios de ciencias «ajenas» a lo económico. Por ejemplo, desde que Nicolay Georgescu-Roegen (17) introdujo el concepto de entropía en la economía, esta última ha entrado en un proceso de reformulación, quizás tan importante como en los tiempos de Marx o Keynes. En efecto, cada vez son más los economistas que no conciben una economía que ignore los gastos en la producción energética, los que a su vez son imposibles de evaluar sin tomar en cuenta la segunda ley de la termodinámica. En este sentido, la noción de entropía es fundamental si se piensa construir un tipo de pensamiento económico que recurra a la ecología a fin de tematizar los problemas derivados de la escasez y no los del «crecimiento». Porque a diferencia de la primera ley de la termodinámica que nos dice que el contenido energético del universo es constante, la segunda no dice que la entropía, o lo que es igual, la cantidad de energía que no es reincorporada a los procesos de reproducción de la naturaleza, crece constantemente. Como precisa Georgescu-Roegen, «una determinada cantidad de entropía puede ser usada por nosotros solamente una vez» (18). En ese sentido, la entropía puede ser también definida como la cantidad de energía que no se convierte en trabajo.

Así como hay formas de producción que no son intensivas en lo que se refiere a la utilización de la fuerza de trabajo humana, hay otras que son intensivas en la producción de entropía. De acuerdo a lo dicho, las economías de crecimiento, en la medida en que se basan en la disipación de altas cuotas de energía, producen, objetivamente, una mayor escasez, más aún si esas economías se dejan guiar, como casi siempre ocurre, por el criterio de la maximización de las ganancias. La economía del crecimiento resulta así antieconómica. Como apunta R. Wilkinson: «En el sentido más amplio del término, desarrollo económico significa el desarrollo de métodos cada vez más intensivos en la explotación del medio ambiente natural» (19).

\footnotetext{
(17) Nicolás Goergescu-Roegen, "The Entropie Law and the Economic Process", Cambridge, 1971.

(18) Op. cit., p. 278

(19) R. Wilkinson, "Poverty and Progress», New York, 1981, p. 102
} 
«La escasez existe porque los procesos entrópicos son irrevocables», afirma con mucha razón Max Neff (20). Y si son irrevocables, en todo proceso de producción es posible establecer la contradicción entre dos tipos de tiempo: el que es propio a ese proceso y el que requiere la naturaleza para su reproducción. Ahora bien, tales tiempos podrían ser diferenciados entre sí por la cantidad de entropía que en cada uno de ellos se produce. Una Segunda Crítica a la Economía Política obligaría, por eso mismo, a una reconsideración del concepto de progreso económico. La aceleración del tiempo que demanda un tipo de producción, en la medida en que acelera los tiempos de producción de entropía, sería un tiempo regresivo, y no ascendente. Mientras más se aumenta la productividad, más tiempo (evaluado en desgaste energético) perdemos. Mientras más la regulamos, más tiempo ganamos.

\section{OCUPANDO ESPACIOS}

El desmontaje de ideas elevadas a categoría de dogmas por la economía del crecimiento nos muestra cómo el estilo de pensamiento que recurra a la ecología puede ir ganando espacios. Estos espacios tienen mucha incidencia al nivel de la política, pero no son necesariamente políticos. O dicho así: antes de constituirse en políticos es necesario que se produzcan «procesos de erosión» en las ideologías oficiales, las que en un determinado momento, para seguir existiendo, no pueden seguir ignorando la presencia de ideas que las cuestionan en su propia esencia. En la «larga marcha de la ecología» (desde los laboratorios más especializados hacia los centros de decisión política) hay momentos en que esta «erosión»se ha hecho manifiesta. Por ejemplo, cuando el año 1972 el «Club de Roma» publicó Los Límites del Crecimiento. Independientemente de la exactitud o no de los datos, estaba claro, desde el momento en que fue publicado, que una grieta muy profunda se había abierto en el medio del consenso desarrollista. A partir de ahí se hizo evidente que no sólo científicos aislados habían reconocido los límites de las ideologías económicas en vigor. Que la publicación de Los Límites del Crecimiento no fue un desliz de algunos economista, lo muestra el hecho de que la ONU ha venido, a partir de ese año, emitiendo informes similares. El año 1987 , por ejemplo, la «Comisión para el ambiente y el desarrollo», dependiente de la ONU, publicaba el Informe Brutland, en donde ya no sólo se describen las catástrofes ecológicas que nos esperan, sino que además se plantea radicalmente la relación existente entre «destrucción del medio ambiente» y el "subdesarrollo», exigiendo, además, reconsiderar el sentido de los proyectos de desarrollo puestos hasta ahora en práctica. Desde una perspectiva de nuevo radicalismo social, los planteamientos esbozados en tal informe pueden parecer insuficientes. Pero, independientemente al contenido declarativo del informe, si se lee atentamente, puede ser considerado como una gran declaración de la bancarrota de las ideologías del crecimiento económico. ¿Cuándo los ministros de Economía de los países latinoamericanos se tomarán la molestia de tı mar notas de esas decla-

(20) M. Neff, «Economía descalza», Buenos Aires, 1987, p. 57. raciones? Ellos, que creen ser modernos frente a los ecologistas, viven en realidad en la «Edad de Piedra» de la Economía.

La ruptura del "consenso desarrollista» es consecuencia de largos procesos de conflictos y discusiones, incluso de fuertes enfrentamientos políticos $\mathrm{y}$, no por último, de relaciones de poder. Pero no siempre las relaciones de poder son relaciones de fuerza. Las relaciones de poder surgen también del poder de las ideas, que son, al fin y al cabo, las que comienzan a imponerse en la política real, antes muchas veces que sus portadores hagan acto de presencia. Lo dicho, que puede aparecer muy ingenuo, sobre todo en América Latina, se deja ilustrar perfectamente con un ejemplo:

En Alemania, el Partido Verde ha logrado estabilizarse políticamente en su condición de minoría parlamentaria, la que por lo demás puede ser muy decisiva para la formación de coaliciones de gobierno estables, fundamentalmente con los socialdemócratas. Sin embargo, nadie podría decir hoy que las ideas ecológicas sólo están representadas en Alemania por los «verdes». Gracias, en parte a los «verdes» ningún programa de ningún partido político puede prescindir de la temática ecologista. Y no siempre por «razones de táctica». Los «verdes» alcanzarán, quizá nunca, la mayoría parlamentaria. Pero las ideas «verdes» están a punto de convertirse en mayoritarias (21).

En los países latinoamericanos, el avance de la «razón ecológica» pareciera estar ahora comenzando. Pero... ¿está verdaderamente ahora comenzando? ¿O quizás está ahora comenzando en las cabezas de algunos miembros de las élites intelectuales? Porque justamente el avance de ideas políticas que recurren al saber ecológico nos puede inducir a leer de una manera diferente nuestra propia historia. Hace quinientos años, por ejemplo, que los más legítimos habitantes de América vienen luchando por el respeto a sus condiciones de existencia y por la defensa de los fundamentos naturales de su reproducción cultural y económica. ¿Por qué lucharon los indios-campesinos de Emiliano Zapata contra Díaz, contra Madero, contra Huerta, contra Carranza y contra quien se les pusiera por delante, sino por la defensa del «ejido», unidad de reproducción social comunitaria y ecológica? ¿Por qué lucharon los indios peruanos y bolivianos desde Tupac Amaru hasta nuestros días sino por la recuperación de "ayllu» basado en la reciprocidad entre los seres humanos y la naturaleza? ¿Por qué lucharon los indios mizkitos frente a los modernizadores revolucionarios sandinistas sino por la defensa de su medio ambiente natural? ¿Por qué luchan los pueblos amazónicos sino para evitar que la Amazonia sea convertida por las grandes empresas en un desierto? ¿Por qué hoy en día los pueblos indios ecuatorianos se organizan políticamente sino para defender sus

(21) Precisamente el hecho de que un nuevo estilo de pensamiento puede imponerse "erosionando" convicciones establecidas, lo prueba un artículo del político alemán Kurt Biedenkopf publicado en el periódico Die Zeit. En ese artículo, Biedenkopf plantea que las «economias industriales» en virtud de un crecimiento que opera sin consideración de los valores ecológicos, se encuentra en una «crisis de limitabilidad». Más aún, señala estar convencido de que el mercado ya no se encuentra en condiciones de ofrecer soluciones, las que sólo pueden provenir de un cambio radical de los modos de pensar dominantes. Ahora bien: semejantes posiciones, hace dos años, sólo eran representadas por las facciones más radicales de «los Verdes» (K. Biedenkof, "Wachstum bis zur Katastrophe» en Die Zeit, núm. 40, 26 de septiembre de 1991, pp. 43-44). 
tierras? No. No es cierto que los temas ecológicos sean nuevos en América Latina. La resistencia ecológica tiene en nuestro continente muchos años. Lo que sucede es que la lectura de «la historia oficial» nos ha impedido reconocer a sus actores. Y los representantes de esa «historia oficial» tienen también sus motivos: reconocer a los actores de la razón ecológica, vale decir, a los defensores más inmediatos de la naturaleza, implicaría revisar el estrecho concepto de nación y de sociedad que ellos poseen. En el fondo, no temen a la ecología; les temen a sus representantes, a quienes con sus incompetentes análisis han condenado al silencio.

Pero la naturaleza también tiene voces.

\title{
RESUMEN
}

Desde el planteamiento de una ecología que en sí no es un discurso, sino un recurso que carece de neutralidad ideológica se aborda una revisión de los enfoques de desarrollo ejecutados en la práctica política latinoamericana y se establece la posibilidad del sentido político de la ecología en cuanto definitorio de unos conceptos distintos de nación y sociedad.

\begin{abstract}
Ecology is not in itself discourse, but a resource which lacks of ideological neutrality. From this point of view, the author realizes a review of the policies developed in Latin America, and he establishes the political sense of ecology in the definition of different concepts of nation and society.
\end{abstract}

